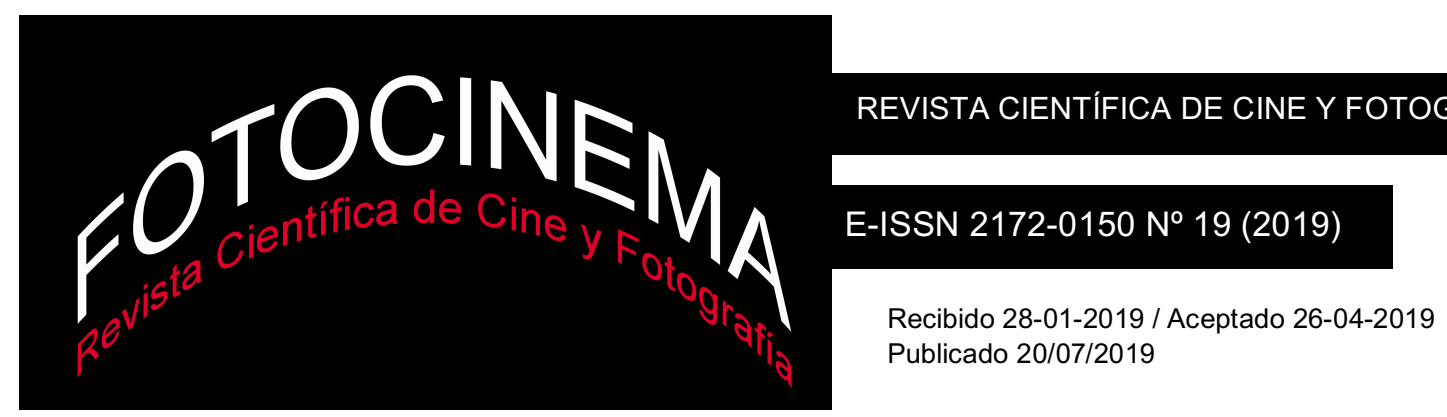

\title{
Shame (2011) de Steve McQueen. El cine en segundo grado: la hipertextualidad
}

\author{
Shame (2011) by Steve McQueen. \\ Cinema in the second degree: Hypertextuality
}

\author{
Manuel Antonio Díaz Gito \\ PTU, Universidad de Cádiz, España \\ manuel.diazgito@uca.es
}

\section{Resumen:}

El objetivo de este trabajo es proponer la existencia de una relación transtextual de hipertextualidad entre Shame (2011), película dirigida por el director británico Steve McQueen, y American Psycho de Mary Harron (2000), adaptación cinematográfica de la novela homónima de Bret Easton Ellis (1991). El fundamento de esta hipótesis descansa tanto en la similitud de los respectivos argumentos y de los recursos cinematográficos (estructurales, transtextuales y retóricos) empleados en las dos películas, como en la intención artística de los cineastas. En un trabajo subsiguiente, se identificará y analizará una serie de citas intertextuales de diferente procedencia también presentes en el filme de McQueen. La superposición de diferentes discursos convierte a Shame en un rico palimpsesto transtextual que proyecta su propio significado a partir de la suma de las significaciones de sus textos subyacentes. Parafraseando la fórmula del semiólogo literario francés Gérard Genette, cuya metodología ha servido de base para el análisis, Shame de Steve McQueen resulta un buen testimonio de "cine en segundo grado".

\begin{abstract}
:
The aim of this paper is to suggest the existence of a transtextual relationship of hypertextuality between Shame (2011), a film by the British director Steve McQueen, and American Psycho (2000) by Mary Harron (on the novel by Bret Easton Ellis [1991]). Firstly, this thesis is supported both by the similarity of the plots and the filmmaking elements, as well as by the artistic intention of their directors. In a subsequent second part of this essay, another series of intertextual allusions from different sources in McQueen's film will be identified and analysed. As a result, the film becomes a meaningful transtextual palimpsest which provides its own meaning from the combination of meanings of its underlying texts. Paraphrasing Gérard Genette's words, the French literary theorist whose methodology has been used in the present analysis, Steve McQueen's Shame is a good example of "cinema in the second degree".
\end{abstract}

\section{Palabras clave:}

Transtextualidad; Hipertextualidad; Gérard Genette; Shame; Steve McQueen; American Psycho; Mary Harron; Bret Easton Ellis.

\section{Keywords:}

Transtextuality; Hypertextuality; Gérard Genette; Shame; Steve McQueen; American Psycho; Mary Harron; Bret Easton Ellis. 


\section{Introducción. Objetivo y presupuestos metodológicos}

Tras su opera prima Hunger (2008), una película de carácter político sobre la huelga de hambre sostenida en prisión por el líder del IRA Bobby Sands, interpretado por Michael Fassbender, el cineasta británico Steve McQueen cambió de asunto, registro y escenario, pero no de actor principal, para la realización de su segundo largometraje, titulado Shame (2011)1. En este drama intimista el intérprete irlandés vuelve a dejarse la piel para encarnar a un apuesto profesional de New York, que, tras su fachada de éxito, esconde una destructiva adicción al sexo².

Con la vista puesta en el objetivo último de explorar las posibilidades de significación de Shame derivadas de su interpretación como un relato de tradición mítica de bajada a los Infiernos, tesis que desarrollo en otro lugar, 3 es mi intención ahora, haciendo uso del análisis del discurso y la metodología de autores postestructuralistas como Gérard Genette y otros 4 , proponer un texto complejo que, a mi entender, funciona como hipotexto de la película. Es decir, como un pre-texto o texto previo del que en cierto modo deriva a modo de reescritura encubierta el relato de Shame ${ }^{5}$.

Como se sabe, Genette parte de los presupuestos teóricos de Mijail Batjín (dialogismo) y de Julia Kristeva (intertextualidad) para proponer su concepto análogo de transtextualidad. La define como la "trascendencia textual del

\footnotetext{
${ }^{1}$ Shame (2011), DVD, Film4, See-Saw Films, UK Film Council, UK. De aquí proceden los fotogramas que ilustran este trabajo.

${ }^{2}$ El empleo del mismo actor en ambas películas puede no ser inocente, pues contribuye a provocar en el espectador asociaciones eficaces entre el hambre física que le ha visto padecer hasta la consunción y la muerte en Hunger y el ansia sexual implacable que desata la tragedia en Shame.

3 Se recomienda leer las dos partes de este trabajo (cf. n. 5), autónomo en sus objetivos y conclusiones, junto con un ensayo sobre el concepto postmoderno de infierno en Shame del que presenté un avance ("Shame (Steve McQueen, 2011) y las Hijas de Dánao") en el $V$ Congreso Internacional de Mitocrítica. Mitos y creación audiovisual, Madrid, 1526/10/2018. Con el título de "El Infierno, según Steve McQueen. Shame (2011) y las Hijas de Dánao", este otro artículo -en su redacción y extensión definitivas- ha sido aceptado para su publicación en la revista norteamericana International Journal of the Classical Tradition 26 (2019), en prensa.

4 Cf. Genette, 1989; Allen, 2000, esp. pp. 95-115; Marinkovich, 1998-1999.

5 Por razones metodológicas y de extensión, he dividido el presente trabajo en dos partes, que se ocupan respectivamente de la hipertextualidad y de la intertextualidad -según criterios genettianos- en Shame de S. McQueen. Espero publicar en breve la segunda parte de este trabajo bajo el título de "iError! Solo el documento principal.Shame (2011) de Steve McQueen. El cine en segundo grado: la intertextualidad”.
} 
escrito, todo lo que pone al mismo en relación manifiesta o secreta con otros textos” (1989, pp. 9-10) y, aunque distingue hasta cinco tipos o grados ${ }^{6}$, concentra su análisis en el más importante de ellos, la hipertextualidad. Básicamente la hipertextualidad analiza las relaciones entre un texto (denominado hipertexto) con otro precedente (hipotexto) del que el primero se sirve mediante su transformación, modificación o reelaboración. Distintos investigadores han adaptado la teoría literaria del semiólogo francés al discurso cinematográfico (Stam, 2005, pp. 26-31; Pérez Bowie, 2008 y 2010; Pardo García, 2010), suministrando la metodología y las herramientas de análisis de las que me he aprovechado en este trabajo.

\section{La hipertextualidad en Shame}

La sinopsis argumental de Shame, a partir de un guion escrito por McQueen y Abi Morgan7, es como sigue: Brandon Sullivan es un atractivo treintañero, ejecutivo de éxito, que vive a su aire en un elegante apartamento en New York. Desde las primeras secuencias se hace evidente que su acusada pulsión hacia el sexo presenta rasgos enfermizos. Su adicción mediatiza su existencia lastrada por la búsqueda de una gratificación sexual instantánea e imposible de colmar. Cuando Sissy, su desamparada hermana menor, cantante en clubs nocturnos, se instala provisionalmente en el apartamento, huyendo de un fracaso amoroso, la fricción surgida de la estrecha convivencia de los hermanos provoca que Brandon se precipite en un pozo de libido, ansia y desesperación que acaba trágicamente.

El hipotexto complejo que, en mi opinión, subyace bajo el relato de Shame al tiempo que lo reescribe 8 es un 'texto' cinematográfico, la película American

6 De menor a mayor grado de implicación entre textos, propone los conceptos de intertextualidad, paratextualidad, architextualidad, hipertextualidad y metatextualidad.

7 Cf. http://www.imsdb.com/scripts/Shame.html [visitado 27/01/2019].

8 Sigo el concepto de reescritura según definición de Pardo García (2010, p. 48): "forma de hipertextualidad consistente en la transposición de un texto en otro que lo repite al tiempo que lo transforma con una intención seria que puede ir desde la actualización y la reivindicación a la crítica y la oposición”. 
Psycho (2000) de la realizadora canadiense Mary Harron", cuyo guion, escrito por la propia directora y Guinevere Turnerio, es, a su vez, la versión cinematográfica de la polémica novela homónima (1991) de Bret Easton Ellis, escritor estadounidense y uno de los grandes exponentes de la Generación X. Centraré mi atención en la relación entre las dos películas, porque la mayor amplitud de audiencia de la adaptación cinematográfica de la novela de Ellis catapultó su capacidad como instrumento de cuestionamiento cultural, social o político, y porque el 'texto' de llegada es una película ${ }^{11}$.

Puesto que toda película es por naturaleza el resultado de la acomodación de un guion previo a las exigencias de la materialización cinematográfica, cuando este, a su vez, es el guion adaptado de una novela preexistente, el proceso de realización multiplica su complejidad. El mecanismo de adaptación al lenguaje cinematográfico de una novela-hipotexto presupone "una compleja serie de operaciones: selección, amplificación, concretización, actualización, crítica, extrapolación, popularización, reacentuación, transculturalización” (Stam, 2005, pp. 45-46) que puede desembocar, según el grado de transformación implicado, en una simple adaptación al nuevo código cinematográfico o una más ambiciosa reescritura que entrañe la apropiación o incluso la revisión del texto de partida (Pardo García, 2010, pp. 64-65). Asimismo, la mayoría de los capítulos que Genette dedica a lo que denomina formas de transposición o transformación seria ${ }^{12}$, las más importantes de las prácticas hipertextuales, que básicamente son responsables de contar lo mismo de manera diferente y que él analiza en el seno del fenómeno literario, son trasladables a los procedimientos de reescritura tanto de un texto literario a un guion adaptado, como de una película a otra película (reescritura filmoliteraria). Por ello he

\footnotetext{
9 American Psycho (2000), Lions Gate Home Entertainment, U.S.A. De aquí proceden los fotogramas que ilustran este trabajo.

${ }_{10} \mathrm{Cf}$. http://www.dailyscript.com/scripts/American_Psycho_Harron_Turner.html [visitado 27/01/2019].

${ }^{11}$ La conexión entre los dos filmes se alude muy tangencialmente en Featherstone, 2016, p. 26: "Akin to Mary Harron's American psycho (2000), which also captures the frozen dialectic of sexual desire and revulsion, the horror of McQueen's Shame resides in its depiction of the main character, Brandon's (M. Fassbender) simultaneous desperate desire for and allergic reaction to intimate relations with others". Véanse la reseña de la adaptación cinematográfica de Harrón, Kauffman (2000-2001) y n. 13.

${ }^{12}$ Las de tipo formal (de reducción o aumento, transmodalización, etc.) y las de tipo temático (transmotivación, transvalorización, etc.).
} 
calificado de 'complejo' el hipotexto que propongo para Shame, por cuanto que American Psycho de Harron es el resultado de sucesivos procesos de escritura y reescritura a distintos códigos semióticos y a cargo de diferentes creadores: de la novela de autor al guion adaptado por las dos coescritoras y de este a su definitiva plasmación cinematográfica, cuya responsabilidad última compete exclusivamente a la directora ${ }^{13}$. Eso sin contar con que la novela original, American Psycho de Ellis, no es ajena a la existencia previa de Psycho (1960) de Alfred Hitchcock, quien, a su vez, con su peculiar manera de hacer había trasladado al celuloide un guion adaptado por Joseph Stephano a partir de la novela homónima de Robert Bloch (1959). Como consecuencia de esta larga cadena de escrituras, reescrituras y sobreescrituras, todavía en Shame atisbaremos ecos intertextuales susceptibles de ser retrotraídos a alguna célebre escena de esta y otras películas de Hitchcock ${ }^{14}$. A todo ello se une que tanto American Psycho como Shame operan en sus respectivas narraciones la reescritura architextual en clave postmoderna del antiguo mito de bajada a los Infiernos ${ }^{15}$.

De partida, lo que, en mi opinión, vincula American Psycho, la novela, pero sobre todo su versión cinematográfica, con Shame, es, en un primer examen, la similitud de un esquema argumental que pivota sobre el desplome psicológico de sus respectivos protagonistas y los recursos cinematográficos

13 Frente a otros proyectos descartados como el de Matthew Markwalder, cf. http://www.dailyscript.com/scripts/american_psycho_unproduced.html [visitado 27/o1/ 2019], el guion firmado por Harron-Turner a partir de una novela tildada de misógina quizás debió de acusar el hecho de que fuese escrito desde las perspectivas de una mujer embarazada y una lesbiana. La complejidad de esta adaptación cinematográfica de la novela de Ellis ha sido resaltada por J. Kooijman y T. Laine: "Rather than considering the film version to be an adaptation of the novel, we argue that the novel and film complement each other" (2003, p. 46).

${ }_{14}$ Por tratarse de vinculaciones de tipo intertextual más que hipertextual, las conexiones remanentes de Shame con el universo hitchcockiano las he reservado para la segunda parte de este trabajo anunciada en n. 5 (como anticipo, las más obvias son el ataque de Sissy en la ducha (cf. Psycho) o la pulsión voyeurística de Brandon Sullivan (cf. La ventana indiscreta. Rear window, 1954). Recordemos que para Genette la intertextualidad es "la relación de copresencia entre dos o más textos..., es decir, como la presencia efectiva de un texto en otro", lo que abarcaría un amplio radio de relaciones como la cita o el plagio o la alusión (1989, p. 10).

${ }_{15}$ Así lo ha entendido en el caso de American Psycho, entre otros, González Etxeberria (2017) y así lo entiendo para el caso de Shame en el trabajo citado en n. 3. Cf. para este tema en general, Holstmark, 2001, y Sánchez-Escalonilla, 2005. La architextualidad genettiana vincula un determinado texto con el género literario o la tradición (también la tradición mítica) de los que forma parte (Genette, 1989, p. 202). 
que se emplean para contarlo. Pero a ello se añade, en un análisis posterior y más profundo, el común significado metafórico, más complejo, de la voluntad artística de los cineastas ${ }^{16}$.

En cuanto al argumento, American Psycho, ambientado en la década de los ochenta, básicamente cuenta -como hará Shame treinta años más tarde- la degradación mental de un joven y atractivo alto ejecutivo de Manhattan, Patrick Bateman (encarnado por Christian Bale) ${ }^{17}$, que vive sin cortapisas en un lujoso apartamento en la milla de oro de la ciudad de los rascacielos. En este caso, el sociópata protagonista se pierde en el laberinto de su mente perturbada y, progresivamente incapaz de distinguir lo real de lo imaginado, acaba convertido en un asesino en serie paranoico (o así lo parece).

Aun así, solo la semejanza argumental general de dos relatos que en el detalle cuentan historias tan diferentes no bastaría para apuntalar una conexión de cierto tipo de dependencia hipertextual si no se identifican además tanto las estrechas afinidades de distinta naturaleza que abogan por la interrelación de las dos películas, como las operaciones de transformación que pudieran ser responsables de las acusadas divergencias entre ellas.

\subsection{Afinidades entre American Psycho y Shame}

\subsubsection{Analogías estructurales}

Ya en cuanto a la estructura que sostiene la narración, los guiones de las dos películas en cuestión se hallan vertebrados sobre un mismo esquema compositivo. Se trata en ambos casos de una composición en anillo ('Ringkomposition'; cf. Holstmark, 1997) determinada por escenas paralelas de apertura y clausura del relato que funcionan como fronteras cronológicas

\footnotetext{
${ }^{16}$ La común intencionalidad metafórica de Shame y American Psycho como denuncia de las disfunciones del sistema capitalista neoliberal ocupa el capítulo final ("Brandon Sullivan y las Hijas de Dánao") del artículo referenciado en n. 3.

${ }_{17}$ McQueen ha elegido un nombre para su protagonista ("Brandon Sullivan") y un actor (Michael Fassbender) que funcionan casi como clones de los de American Psycho ("Patrick Bateman", Christian Bale).
} 
de la trama y como diapasón de medida de la evolución psicológica de sus respectivos protagonistas.

American Psycho, la película, comienza y acaba con sendas escenas de inane conversación entre colegas yuppies ${ }^{18}$ ambientadas en uno de los locales elitistas de Manhattan que son su codiciado objeto de deseo a lo largo del metraje (F1 y F2). Estos hiperlujosos restaurantes y clubs, hábitat natural de esta casta de cachorros privilegiados, funcionan como símbolo diferenciador y excluyente de su estatus social y económico vinculado al triunfo del sistema capitalista neoliberal de la década de los ochenta amparado por los teóricos de la Escuela de Chicago ${ }^{19}$.

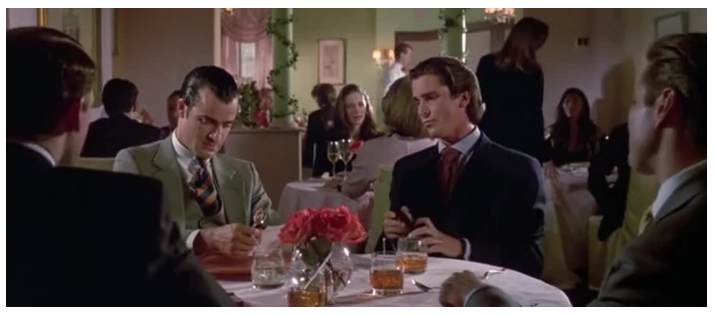

F1. Escena inicial (Amer. Psycho)

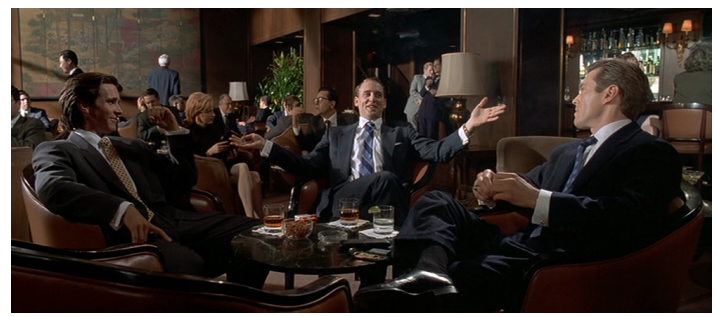

F2. Escena final (Amer. Psycho)

Por su parte, Shame comienza y acaba con escenas simétricas de muda seducción en un vagón de metro $\left(\mathrm{F}_{3}\right.$ y F4) ${ }^{20}$. Que en ambas escenas se trate del improbable encuentro con la misma mujer anónima en una ciudad de ocho millones de habitantes enfatiza la dirección circular de la composición narrativa. Este escenario subterráneo del metro neoyorkino asoma en otros pasajes de la película como leitmotiv de reminiscencia infernal, por lo que por su recurrencia y función significativa sería el equivalente en Shame de los exclusivos locales de moda que figuran en American Psycho.

\footnotetext{
18 Acrónimo para "Young Urban Professionals", neologismo de uso frecuente durante los ochenta para designar a una persona joven con estudios universitarios, habitante de una ciudad y con un trabajo de muy alto nivel que le procura un estatus económico y social privilegiado (cf. Algeo, 1991, p. 220).

${ }_{19}$ La feroz competitividad que alienta el sistema aparece en la película ridiculizada en la soterrada envidia que despierta en ellos la rivalidad por el lujo (la posesión de la tarjeta de visita más elegante, la propiedad del apartamento más caro o la capacidad por conseguir lo imposible: una reserva en el restaurante más exclusivo, el Dorsia).

${ }^{20}$ Podríamos rastrear el germen de esta idea en una escena incidental de American Psycho, cuando Bateman seduce sin palabras a una mujer en plena calle durante el intervalo del cambio de señal de un semáforo.
} 


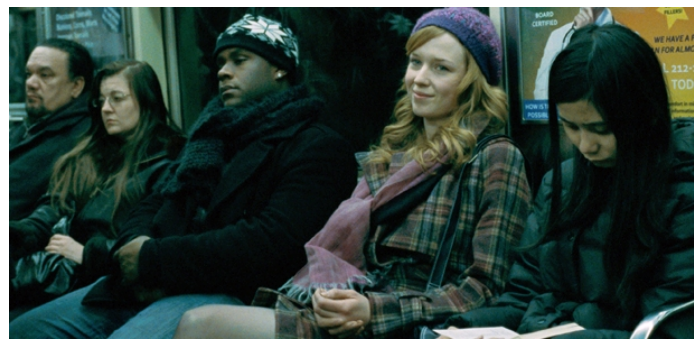

F3. Escena inicial (Shame)

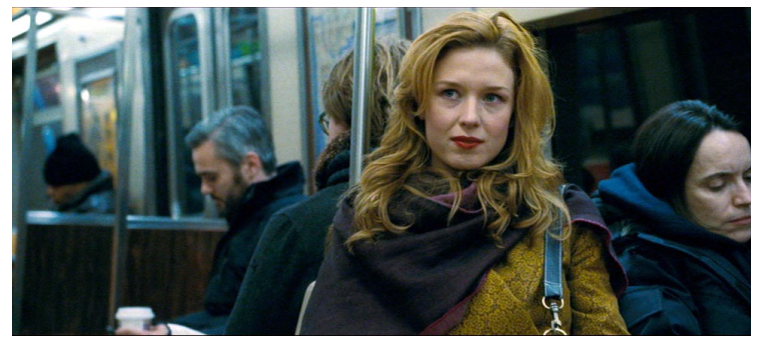

F4. Escena final (Shame)

De esta manera lo que se nos cuenta en ambos filmes es un fragmento breve, pero crítico, de la vida de sus personajes principales delimitado por el intervalo temporal entre esos dos momentos (preliminar y postliminar). La circularidad del relato, junto con la deliberada falta de contexto biográfico y psicológico de los protagonistas, contribuye a dotar de mayor ambigüedad el desenlace de la propuesta dramática. En este sentido, la reflexión de Laura E. Tanner acerca de la novela de Ellis se puede hacer extensiva naturalmente a su versión cinematográfica: “The novel's lack of closure, characterization and plot makes it archetypically postmodern" 21 . Pero igualmente se puede aplicar al relato que nos propone Shame.

Me atrevería incluso a sugerir que esta estructura narrativa circular juega con la idea de eterno retorno característica de las penas de los condenados a sufrir en el Hades clásico (véase un prototipo como Sísifo): no en vano la peripecia de uno y otro protagonista puede ser analizada bajo la horma del relato mítico de catábasis, un descenso psicológico a los infiernos del alma humana ${ }^{22}$.

Por otro lado, en lo que respecta a Shame, en las dos escenas situadas en el metro ya aludidas el anillo de casada de la mujer seducida adquiere un momentáneo protagonismo mediante un fugaz plano detalle. Además de su valor en el plano intradiegético, 23 este gesto puede funcionar como un recurso

${ }^{21}$ Cit. por González Etxeberria, 2017, p. 280. La adaptación cinematográfica de American Psycho acentúa este aspecto prescindiendo de cualquier referencia al hermano o la madre de Bateman, que sí asomaban en la novela de Ellis.

${ }^{22}$ Cf. $n .15$ y el texto al que hace referencia. El interés de Ellis por el tema de la catábasis se renovó en la revisitación del mito de Orfeo que realizó en 2015 para una campaña publicitaria (https://www.selectspecs.com/fashion-lifestyle/bret-easton-ellis-persol-join-forces-on-neworpheus-campaign/ [visitado 27/01/2019]).

${ }_{23}$ Durante la discusión final con Sissy, Brandon recrimina a su hermana su aventura con David, su jefe, un hombre casado (“¿No le viste su alianza de boda en el dedo?”), como si eso hubiese sido un obstáculo en su propio comportamiento previo en la escena inicial del metro. 
metacinematográfico tanto de carácter retórico como ideológico. Desde el punto de vista retórico puede no ser casual la focalización sobre un anillo (en una mano que además se cierra en círculo en torno a la barra del vagón) justo en las dos escenas que delimitan estructuralmente la composición 'anular' del relato. Desde el punto de vista ideológico, la alianza de la mujer a la que persigue Brandon y a la que pierde en el umbral de salida del metro favorece la interpretación de esta escena en clave de reescritura architextual del mito de Orfeo y su 'esposa' Eurídice, situando al espectador desde los primeros compases de la película en el terreno de la catábasis infernal. La estructura circular resulta especialmente apropiada para un relato de un viaje de ida y vuelta o de descenso y ascenso (catábasis y anábasis) y por lo mismo fue frecuentemente usada en la literatura clásica para narrar la inmersión infernal de Orfeo.

Y así, sobre todo en el guion de Shame, diseñado con absoluta precisión, la vertebración especular determinada por la 'Ringkomposition' impone una larga serie de simetrías intradiegéticas que recojo en la siguiente sinopsis:

\section{Título inicial: SHAME (paratexto)}

A. A. Escena de seducción en el metro (primer plano de la alianza de la joven).

B. Deconstrucción de la narrativa lineal mediante un montaje fragmentado de tres escenas (escena de seducción en el metro/visita de la prostituta/rutina diaria de Brandon). BSO: tema: Brandon (8m 33s).

C. Tres actantes: Brandon/Sissy $/+3^{\circ}$ actante (David, el jefe de Brandon: encuentro con Sissy en el club nocturno y aventura sexual). Mensajes perdidos de Sissy en el contestador automático. Escena de crudo sexo con una desconocida. Escena del baño (Brandon sorprende a Sissy desnuda en la ducha). Bronca entre los hermanos (Brandon echa a Sissy de su habitación). Monólogo desesperado de Sissy al teléfono. Brandon, voyeur auditivo (espía la conversación de Sissy al teléfono con su exnovio). Prenda vintage -sic- (el “sombrero loco” de Sissy). Primer 'suicidio' y rescate de Sissy en la vía del metro. Brandon, frente al portátil (con una botella de cerveza, en la

Es un medio más del guion para subrayar la relación especular y simbiótica de estas dos almas gemelas. 
cocina). Cicatrices antiguas en el brazo de Sissy. Largo travelling horizontal hacia la izquierda (Brandon corre huyendo de Sissy).

D. Axis central: Brandon intenta un cambio de rumbo en su vida.

C'. Tres actantes: Brandon/Sissy $/+3^{\circ}$ actante (Marianne, la colega de Brandon: cita con Brandon en el restaurante y aventura sexual). Brandon, voyeur visual (espía a la pareja exhibicionista en el bloque de apartamentos). Escena del baño (Sissy sorprende a Brandon desnudo mientras se masturba). Sissy, frente al portátil (con una botella de cerveza, en la cocina). Prenda vintage -sic- (las bragas anticuadas de Marianne). Escena de crudo sexo con una conocida. Bronca entre los hermanos (Brandon echa a Sissy de su apartamento y de su vida). Mensajes perdidos de Sissy en el contestador automático. Monólogo desesperado de Sissy al teléfono. Largo travelling horizontal hacia la derecha (Brandon corre hacia Sissy). Suicidio y rescate de Sissy. Cicatrices antiguas y nuevas en el brazo de Sissy.

B'. Deconstrucción de la narrativa lineal mediante un montaje fragmentado de tres escenas (bar de la paliza/club gay/prostíbulo). BSO: tema Unravelling (9m 42s).

A'. Escena de seducción en el metro (primer plano de la alianza de la joven)

Título final: SHAME (paratexto)

\subsubsection{Analogías transtextuales}

Bajo este epígrafe destacaré varias de las numerosas escenas de American Psycho que encuentran eco en la película de McQueen. La acumulación de este tipo de paralelismos hace poco probable que se puedan justificar como simple fruto del azar. Es cierto que algunos de ellos podrían derivarse de manera independiente a partir de la identidad del locus de los respectivos argumentos (el paisaje icónico del horizonte urbano neoyorkino; los despachos -diáfanos, luminosos, acristalados- de las empresas americanas de 'cuello blanco'24; los pulcros, fríos y minimalistas apartamentos -dominados por la impersonalidad

24 En ninguna de las películas se puede deducir mucho acerca de la naturaleza de estas empresas más allá de que en un caso parece tratarse de una firma financiera de altísimo nivel y en el otro de una más modesta compañía publicitaria o tecnológica (en ellas ninguno de los protagonistas parece que haga algo productivo, lo que desde luego en el caso de Bateman es un hecho). 
y la asepsia cromática- de estos solteros de oro). ${ }^{25}$ Incluso podrían ser producto de la casualidad vinculada a este ambiente privilegiado otras situaciones como las de la congregación masculina de los colegas de trabajo en elegantes clubs, ${ }^{26}$ descriptivas de una sociedad patriarcal y machista (y acentuadamente clasista, racista y misógina en American Psycho); las del camarero extremadamente solícito recitando la carta del menú; o las de los respectivos protagonistas consumiendo coca en el baño.

Pero otras situaciones más particulares, algunas tan específicas que difícilmente pueden ser fortuitas, parecen calcadas de manera deliberada de una película a otra. A saber:

a) El paseo de Brandon desnudo por su apartamento en el arranque de Shame es una reescritura literal (acaso con deliberada función programática) de la secuencia también inicial de American Psycho. Ambas escenas acaban con un encuadre idéntico: un plano figura con la imagen del protagonista al fondo, de espaldas, mientras orina en el baño con la puerta abierta, índice del grado de confortable independencia y autosuficiencia en la que se hallan instalados (F5 y F6).

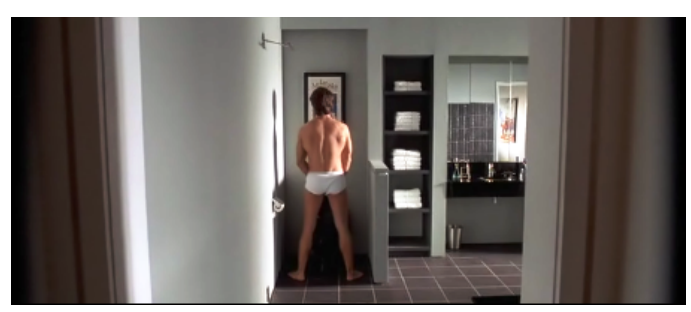

F5. Bateman en el baño (Amer. Psycho)

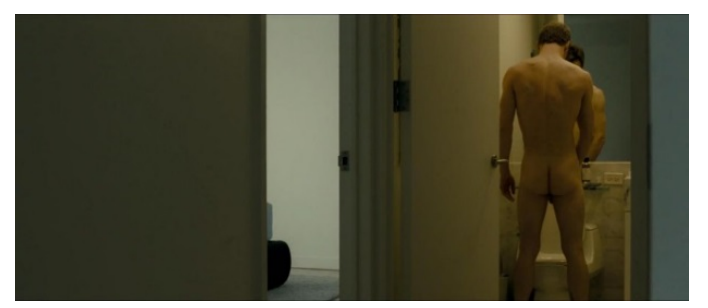

F6. Sullivan en el baño (Shame)

b) La recreación de la cámara en el desnudo masculino como indicio de la personalidad egocéntrica de los protagonistas (obsesivamente narcisista en

25 En American Psycho la cuestión es quién posee el mejor apartamento que denote su posición relativa en la cumbre de la pirámide social; en Shame se trata de tener o no un apartamento propio como presunto indicio de éxito o fracaso en la vida.

${ }_{26}$ Aun así, estos escenarios, separados por tres décadas, son anacrónicamente familiares entre sí. En una entrevista al director, la periodista se sorprendía de ello: - Krista Smith: "When I first saw Shame, the era struck me-it's almost like it could've been 8os-era New York". Vanity Fair (02/12/2011), (cf. https://www.vanityfair.com/hollywood/2011/11/Director-SteveMcQueen-on-Shame-Its-Not-About-Sex-Its-About-Giving-Audiences-Something-to-ThinkAbout [visitado 27/01/2019]). 
el caso de Bateman): cf. el plano cenital de Bateman en la mesa bronceadora/el de Sullivan en la cama ${ }^{27}$.

c) Las escenas de los protagonistas pagando por los servicios de una prostituta y dándole indicaciones precisas de cómo actuar para complacer mejor sus apetitos y la escena subsiguiente en que aparecen juntos en la cama después del acto sexual; o la del trío sexual con dos prostitutas.

También parecen poco casuales situaciones análogas como las del atractivo instantáneo del protagonista con desconocidas; los dos protagonistas son consumidores de porno; los dos tienen alergia al contacto humano y a los dos les molesta el desorden ajeno en su apartamento (Bateman es un maniático); los dos protagonizan una escena de exhibicionismo (Bateman, mientras graba sus actos sexuales en vídeo; Sullivan, cuando practica sexo delante del ventanal de un edificio); etc.

Pero más significativa me parece una serie de elementos de guion, equivalentes y fundamentales para la resolución del relato, que se acumulan en el tramo final de ambos filmes:

a) Uno de los personajes principales femeninos descubre la oscura personalidad secreta del protagonista (Jean, la secretaria de Bateman, cuando decide fisgonear la agenda de su jefe y la encuentra plagada de obsesivos garabatos de extremo sadismo; Sissy, al asomarse al portátil de su hermano y toparse con una de sus compañeras de juegos cibernéticos insinuante y semidesnuda).

b) El protagonista fracasa en su interrelación con la mujer-ángel (Bateman solo logra resistir su pulsión asesina durante el encuentro con Jean, su inocente secretaria; Marianne, la colega de trabajo con la que Brandon intenta cambiar de vida mediante una cita romántica, es la única mujer con la que no es capaz de consumar el acto sexual).

c) Escenas de ruptura con la protagonista femenina que acaban con la mujer en lágrimas y anteceden a la bajada a los infiernos del protagonista:

\footnotetext{
${ }^{27}$ En el caso de American Psycho evoca la aséptica frialdad de un cadáver en una mesa forense; en Shame, quizás, el Lamento sul Cristo morto (1475-78) de Andrea Mantegna.
} 
Patrick rompe con su novia y huye del restaurante/Brandon discute con su hermana echándola de casa y huye del apartamento. ${ }^{28}$

d) En la resolución de las dos tramas adquiere gran relevancia un mensaje telefónico inatendido caracterizado por la desesperación más absoluta (la confesión de Bateman a su abogado/la petición de auxilio de Sissy).

e) En los últimos compases de las dos películas aparece el protagonista envuelto en la sangre de su "víctima" (lo sea esta de manera literal o no).

f) El primer plano del desquiciamiento psicológico de Bateman, tirado en el suelo de su oficina, halla su perfecto paralelo en uno de los planos finales de Shame, que muestra la devastación emocional de Sullivan, derrumbado en el muelle del río Hudson (F7 y F8).
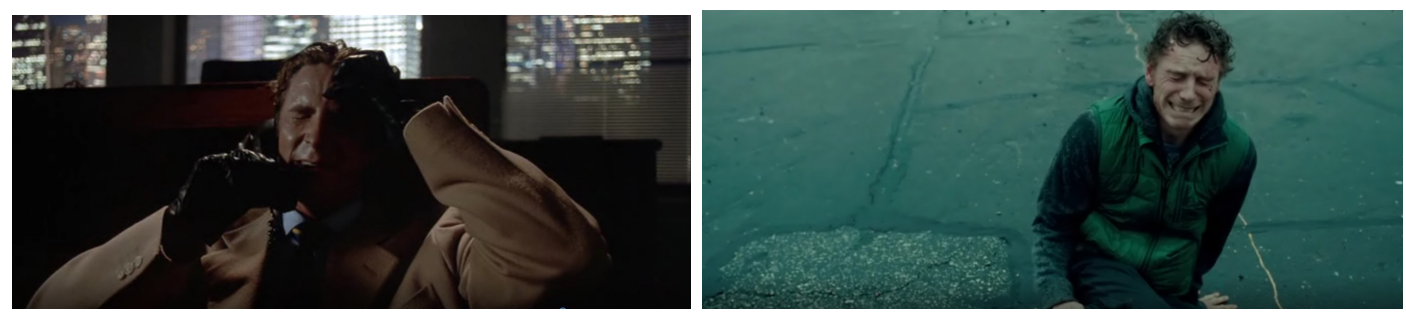

F7. Desolación de Bateman (Amer. Psycho) F8. Desolación de Sullivan (Shame)

g) Y, en último término, las dos películas acaban con un primer plano sostenido de sus respectivos protagonistas que interpela al espectador.

\subsubsection{Analogías retóricas}

Encontraremos nuevas conexiones entre las dos películas si atendemos ahora a los medios cinematográficos utilizados por sus directores, empezando por el empleo de una banda sonora consistente con la trama, un recurso de primera magnitud.

En American Psycho extravagantes disertaciones sobre la música pop de los ochenta están incorporadas en el discurso errático de su locuaz protagonista,

\footnotetext{
${ }^{28}$ Incluso los recitados de los actores presentan coincidencias. En American Psycho, Bateman le dice a Evelyn "Stop making this scene right now" y poco después corta la conversación con un seco "I'm going". En Shame Sullivan le dice a Sissy "Stop playing the victim..." y, antes de irse, añade "I'm going out".
} 
lo que contribuye al dibujo de su anómalo perfil psicológico. En Shame los temas musicales asociados al hermético Brandon son - muy adecuadamentepiezas instrumentales de música clásica de Bach interpretadas a piano por Glenn Gould (1932-1982), un genial músico de personalidad rayana con el autismo. Además, las Variaciones Goldberg de Bach BWV988 vinculadas a Brandon son las mismas que se habían usado para acentuar la conjunción de buen gusto y aberración caníbal del psicópata protagonista en El silencio de los corderos (The silence of the lambs, Johnattan Demme, 1991). Mediante el empleo de esta pieza musical McQueen parece querer insinuar la conexión de su película con uno de los obvios precedentes de American Psycho ${ }^{29}$, al tiempo que deja asomar una sutil sugerencia entre la urgencia del hambre insana de Hannibal Lecter, el impulso asesino de Bateman y el ansia sexual de Sullivan. Por otro lado, además del caso de New York, New York (véase infra n. 33), habría que destacar la incorporación del tema I want your love (1978) de Chic. Esta canción es el más significativo de los temas de la banda sonora de Shame, pues en el guion original la irrupción de Sissy en el apartamento de su hermano venía subrayada por la mención a una canción concreta que estaría sonando en la vivienda, I feel love de Donna Summer (1977). El tema de Summer, poco adecuado en el contexto por su matiz explícitamente erótico, ha sido finalmente sustituido por este otro, cuyo título, I want your love, sirve como paratexto $^{30}$ para acentuar el carácter dependiente, pero transparente y comunicativo, de Sissy.

Pero es más. En ambos filmes llama la atención que canciones emblemáticas del pop anglosajón de los ochenta se hallen pespunteadas por el contrapunto de unos breves temas instrumentales a piano ${ }^{31}$. Y, si en el caso de American Psycho la elección del repertorio musical para su columna sonora está

\footnotetext{
${ }^{29}$ Cf. un estudio sobre la figura del asesino en serie en las novelas de Thomas Harris y Bret Easton Ellis, en Baelo Allué, 2002.

${ }^{30}$ La paratextualidad, según Genette, comprende las relaciones entre el texto mismo y todos aquellos materiales significativos situado al margen del texto (en el cine, desde el título, hasta las entrevistas al director o los temas musicales).

${ }^{31}$ De M.J. Mynarski y John Cale, en un caso; de Bach, interpretados por Glenn Gould, en el otro.
} 
justificada por la época en que se sitúa el relato32, ¿cómo explicar que las canciones que se oyen en Shame, ambientada treinta años más tarde, en 2011, sean también éxitos de los ochenta?33 Es decir, con respecto a la época en que transcurre la acción, estas canciones parecen fuera de contexto, resultan tan 'vintage' como el sombrero loco de Sissy o las bragas anticuadas de Marianne. Por cierto, los discos de vinilo que aparecen en Shame (al igual que las revistas y vídeos pornográficos) son más representativos de la década de los ochenta que de la generación de los millennials que encarna el personaje de Brandon. Su velada relación de dependencia hipertextual con American Psycho podría ser la clave de estos aparentes anacronismos34. En definitiva, el uso de la música también relaciona la película de McQueen con American Psycho, especialmente con su versión para la gran pantalla.

Por último, también desde el punto de vista de los recursos retóricos cinematográficos encuentro sintonía entre las dos películas en el uso frecuente que hacen de la imagen reflejada del protagonista, especialmente en un espejo, con función caracterizadora, como medio de sugerir su carácter psicopático (F9 y F10). La esquizofrenia paranoide de Bateman se nos muestra reflejada en su torso multiplicado en el espejo del baño (o en su rostro en el filo del hacha asesina en el cartel de la película); en el caso de Sullivan, su imagen duplicada en los cristales del baño (o distorsionada en el escaparate de la calle) sugiere el tormento de la depresión.

\footnotetext{
$3^{2}$ Toda la década está representada, desde "Walking on sunshine" (1983, Katrina and the Waves), pasando por "Sussudio" (1985, Phil Collins), "The greatest love of all (instr.)" (1985, Whitney Houston), "Hip to Be Square" (1986, Huey Lewis and the News) y otras, hasta "Who feelin' it" (2000, Tom Tom Club) y "Watching me fall" (2000, The Cure).

33 Además de "New York, New York" (de 1977, pero convertida en éxito por Sinatra tres años después), las canciones de Shame datan de principios de los ochenta. Son éxitos de artistas asociados a la escena musical neoyorquina. Suenan "Rapture" (1980, Blondie), "Genius of Love" (1981, Tom Tom Club) y "I want your love" (1978, Chic). Glenn Gould, intérprete de la música clásica, murió a principios de esa década. Por último, no habría que descartar un guiño explícito a American Psycho: no solo porque las películas comparten sendos éxitos de Tom Tom Club, sino porque "Who feelin' it", el tema de Tom Tom Club presente en la película de Harron, pasa por ser una actualización de "Genius of Love", el tema de la misma banda elegido para Shame.

34 Cf. también n. 26.
} 


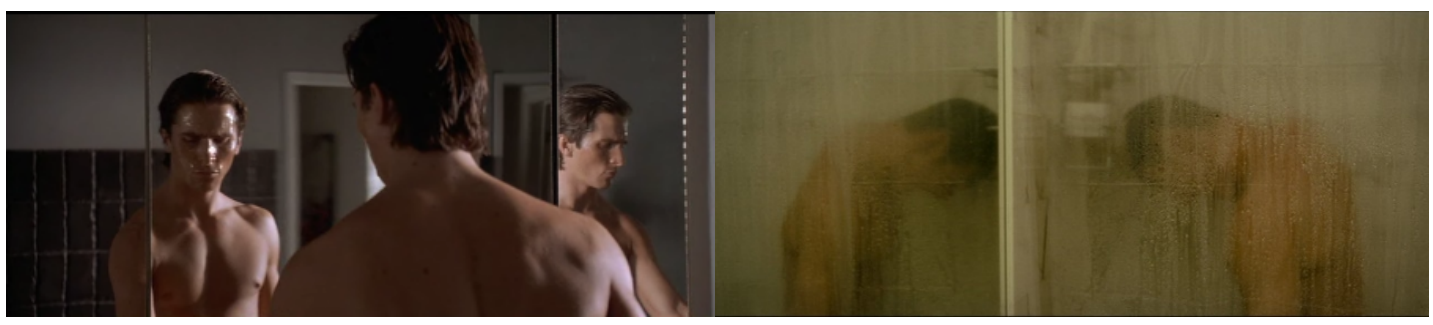

F9. Bateman en el espejo (Amer. Psycho)

F10. Sullivan en el espejo (Shame)

\subsection{Operaciones de transformación}

$\mathrm{Si}$, como parece apuntar el cúmulo de afinidades estructurales, transtextuales y retóricas analizadas hasta aquí, aceptamos la hipótesis de que American Psycho pueda estar latente de alguna manera bajo el relato de Shame, habrá que dar cuenta ahora de los procedimientos de transformación que explican las manifiestas diferencias entre ambas películas 35 .

\subsubsection{Transformaciones formales}

De las diversas transformaciones que pueden afectar a la forma externa de presentación del relato, en nuestro caso merece comentario la denominada transestilización (Genette, 1989, pp. 285-291), responsable de operar un cambio de estilo en el hipertexto. Mucho se ha escrito del carácter elusivo de la novela de Ellis y de su versión cinematográfica, pero tanto una como otra no se entenderían cabalmente sin considerar su alto contenido de humor, exageración y parodia, que hace de ellas una sátira despiadada del sistema capitalista neoliberal caracterizado por un consumismo exacerbado que se hace extensible al ámbito de las relaciones personales ${ }^{36}$. McQueen opta por desactivar esta perspectiva satírica responsable de cierta distorsión distanciadora de la realidad. Su acercamiento objetivo a la peripecia de sus personajes se podría entender como un cambio de estilo: la historia de

35 Seguiré la división tripartita de tipos de transformaciones (formal, temática y semántica) de Pardo García (2010, pp. 48-49), que corrige la distinción dual de Genette (formal y temática/semántica).

${ }^{36}$ Exploran esta dimensión sociológica para el caso de American Psycho, entre otros, estudios como los de Robinson (2006) o Lee (2013). 
Brandon Sullivan (y de su hermana) se enmarca dentro del drama psicológico, cercano al de una tragedia postmoderna.

En otro orden de cosas, la personalidad de los protagonistas de las dos películas se define por un semejante aislamiento y déficit emocional y por su sometimiento exponencial a sus urgencias psicopáticas (de carácter asesino o sexual). Mutatis mutandis y siempre rebajado de grado debido a la renuncia a la perspectiva hiperbólico-satírica, Brandon Sullivan podría pasar por un replicante millennial del yuppie Patrick Bateman de los ochenta. Incluso la diferencia más acusada en el carácter de uno y otro parece resultado de un proceso de inversión deliberado. En American Psycho el personaje de Bateman se halla caracterizado por su desmesurada locuacidad, tanto como Sullivan lo está en Shame por su incapacidad para expresarse y comunicarse. De ahí que en el filme de Harron sea Bateman el narrador que cuenta su historia en primera persona mediante su voz en-off imponiendo así al espectador su paranoica y poco confiable visión de la realidad y de ahí también que en el momento crucial sea él quien descarga el peso de su culpa reconociendo su enfermedad mental en una enloquecida confesión depositada en un contestador telefónico. En Shame, en cambio, contemplamos la vida de Sullivan a través de su mirada (en ocasiones voyeurística) más que de su palabra y por eso él es el receptor mudo del último y fatal mensaje telefónico de su hermana; dada su incapacidad comunicativa, el reconocimiento de su adicción solo puede ser un inarticulado grito ahogado en una de las últimas secuencias de la película. Aunque esta divergencia de partida tiene inevitables consecuencias en el plano temático, podría contemplarse en primer término como un caso atenuado de lo que Genette llama transvocalización, es decir, una transformación de tipo formal consistente en un cambio de voz narrativa (1989, pp. 370-373); digo atenuado porque, aunque se produce el paso de la narración intradiegética de la primera persona (caracterizada por su falta de fiabilidad perceptual) al narrador heterodiegético, no obstante, se sigue asumiendo, ahora con presunción de objetividad, el punto de vista único del personaje principal. Es decir, en ninguna de las dos películas el espectador ve 
algo que no sea a través de sus protagonistas, que lo son, así, de manera absoluta.

\subsubsection{Transformaciones temáticas}

Aunque la transformación diegética más frecuente suele ser la que afecta a los cambios espacio-temporales, lo que Genette llama aproximación, McQueen apenas ha aprovechado las posibilidades que le brinda este tipo básico de transformación temática. Si bien es cierto que ha aproximado el relato a su propia época, lo ha hecho sin alterar las coordenadas geográficas ni el universo social o nacional del hipotexto, que sigue siendo, aun en un escalón inferior, la élite económica de la ciudad norteamericana de New York37. Además, como hemos visto, parece dejar ciertos "anacronismos" que, como un rastro de migas de pan, vinculan su relato con la década de los ochenta de su hipotexto.

Tanto en Shame como en American Psycho, New York adquiere categoría emblemática de tercer protagonista del drama. La icónica metrópolis representa el axis mundi del universo capitalista, el entorno donde se hacen realidad -o no- las aspiraciones al triunfo que promociona y del que se nutre el modo de vida neoliberal que a través de la peripecia de los protagonistas se somete, aunque de manera oblicua y no declarada, a crítica $^{38}$. No por casualidad en uno de los momentos más emotivos de Shame asistimos a la conmovedora interpretación del estándar musical "New York, New York" a cargo de Sissy: se trata de una versión lastimosa, casi un oxímoron musical, que subvierte el optimista mensaje original del tema, un himno que en las enérgicas voces de Minelli o Sinatra celebraba la fe en el éxito en la ciudadque-nunca-duerme. Ahora bien, la isla de Manhattan y Wall Street eran en la obra de Ellis el escenario necesario para documentar los excesos de uno de los amos del mundo surgidos al calor del capitalismo salvaje de los ochenta (cf. el personaje de Gordon Gekko de Wall Street, Oliver Stone, 1987). Sin embargo,

\footnotetext{
37 En American Psycho la imagen de Reagan en un informativo televisivo data con exactitud la época que denuncia la sátira (1981-1989), época que aparece acentuada por la banda sonora (cf. n. 32). En Shame el momento de la acción es más vago (en televisión los hermanos ven unos indeterminados dibujos animados, lo que al mismo tiempo sugiere la inmadurez de los dos).

${ }^{38}$ Cf. n. 16 y n. 36.
} 
la ciudad de los rascacielos no es imprescindible para el retrato de un sexoadicto que propone el director británico: cualquier otra ciudad -de hecho, casi cualquier lugar con acceso a internet- hubiese servido para satisfacer las demandas narrativas de Shame. Así, la falta de una translación espacial (Genette, 1989, p. 263) que hubiese sido consecuencia natural del cambio de asunto de la película de McQueen aboga positivamente como marca de hipertextualidad y, por tanto, la elección de New York -si no es por su evidente proyección fálica $y$, en este sentido, cualquier otra megalópolis hubiese servido- podría interpretarse como un guiño, otro más, al hipotexto propuesto. En todo caso, se detecta una inversión de tipo espacial en el sentido del movimiento de viaje al infierno efectuado por los protagonistas de cada película. En American Psycho la catábasis psicológica, contrariamente a la norma establecida por la tradición, es, desde el punto de vista del desplazamiento físico, de tipo ascendente, en dirección a los rascacielos, mientras que en Shame recupera su convencionalidad al trasladarse al escenario subterráneo del metro y a la oscura claustrofobia del club de sexo gay.

La transmotivación, o sustitución del motivo que mueve a un personaje, es uno de los procedimientos mayores de la transformación temática. En Shame se ha pasado de la psicosis de Bateman, que le impulsa a asesinar de las maneras más execrables e indiscriminadamente (en serie) y que desemboca en un estado literal de demencia, a la neurosis de Sullivan, que lo ata a la persecución de una gratificación sexual también indiscriminada (en serie) al margen del deseo o el afecto y que lo conduce a la desesperación más absoluta. En definitiva, McQueen, sin dejar de documentar un caso de descenso infernal de tipo psicológico que encuentra ya elaborado en su hipotexto, ha convertido en un serial fucker al serial killer de American Psycho, pudiendo aprovechar así también el carácter de icono del capitalismo vorazmente despiadado de este último para hacerlo extensivo al del protagonista de Shame. Y es que sostengo que lo que a los directores de ambas películas les interesa trasladar a la audiencia es, sobre todo, la capacidad arquetípica de sus protagonistas, que son contemplados como una especie de 'caso clínico', es decir, como la 
realización individual de un fenómeno más general. Para ello se sirven tanto del carácter postmoderno de unos personajes carentes casi por completo de los apuntes biográficos que permitirían reconstruir el proceso psicológico que los ha conducido a esa situación 39 , como del valor arquetípico universal que les confieren sus respectivas experiencias míticas de descenso a los Infiernos. Lo que nos lleva a plantearnos la cuestión de si Shame pretende o no un cuestionamiento ideológico de su hipotexto.

\subsubsection{Transformaciones semánticas}

La historia que propone Shame presenta un profundo desplazamiento temático merced a abundantes transformaciones respecto de lo que nos cuenta American Psycho, las más importantes de ellas son las que acabo de señalar en el epígrafe precedente. Pero este radical desplazamiento temático no va de la mano de una similar transformación en el plano pragmático, que es precisamente lo que hace que sea posible vincular las premisas ideológicas de las que parten uno y otro relato. Es decir, la sobreescritura que opera Shame sobre el relato previo de American Psycho no altera sustancialmente su significado metafórico original, que no era otro que la denuncia del consumismo absoluto y deshumanizador del sistema capitalista neoliberal. Shame se limita a proyectar esta denuncia treinta años más tarde en un nuevo contexto narrativo, menos elitista y, por tanto, más cercano al de la audiencia del filme ${ }^{40}$. Su intención, igualmente crítica, es demostrar así no solo la

\footnotetext{
39 Frente a otros muchos psicópatas cinematográficos, cuya criminal demencia, a partir del caso modélico de Norman Bates de Psicosis, es producto de una infancia traumatizada, el silencio sobre el pasado biográfico de Bateman y de Sullivan permite que el origen de su mal moral sea interpretable como el resultado de una sociedad disfuncional. No es la familia, es el sistema el que engendra el monstruo.

40 El adjetivo "American" puede ser entendido como una etiqueta 'architextual', el tipo de transtextualidad de Genette que abarca las relaciones genéricas de un texto. Se vincula así la novela de Ellis y su adaptación al cine con la clase de obras que pretenden dar su visión general de la sociedad estadounidense a partir de un relato particular significativo, como American Pastoral (1997), novela de Philip Roth recientemente llevada al cine por Ewan McGregor en 2016. Entre ellas habría que destacar American graffiti (1973, George Lucas), American Gigolo (1980, Paul Schrader), American History X (1998, Tony Kaye), American Beauty (1999, Sam Mendes), American Gangster (2007, Ridley Scott). Aunque la intención de representar un prototipo humano es la misma en ambos casos, McQueen dota a su antihéroe de mayor universalidad al prescindir del adjetivo "American", trascendiendo así el microcosmos de la élite neoliberal de yuppies que dibuja American Psycho y donde Bateman es solo el primus inter pares de una serie clonada de individuos asociados al poder económico y la falta de escrúpulos producto del sistema capitalista tardío.
} 
vigencia y actualidad en el mundo contemporáneo de las disfunciones del sistema capitalista que se originaron en los años ochenta, sino sobre todo su capacidad de extensión, de contagio exponencial (como si de un virus se tratase, potente metáfora presente en la película tanto en el parlamento inicial -y, por tanto, con carácter programático- de David, el jefe de Brandon, como en el virus que infecta su ordenador y, por extensión, su vida entera). Esta recontextualización repleta, como hemos visto, de sugerencias retrotraibles al hipotexto propuesto, responsables de dejar en el espectador una sensación de deja-vú, conserva la virtud de 'conectar' la neurosis de la sociedad postmoderna encarnada en el protagonista de Shame con los cambios producidos en el sistema durante el mandato de Reagan y que originaron las disfunciones de las que surgía el psicópata protagonista de American Psycho y de las que es heredera nuestra sociedad contemporánea.

\section{Conclusiones}

La tesis de este trabajo ha partido del presupuesto enunciado por Julia Kristeva "todo texto es absorción y transformación de otro texto"41, que fue reformulado por Gérard Genette en su concepto más amplio de transtextualidad.

Todos los argumentos desgranados hasta aquí permiten, en mi opinión, proponer American Psycho de Ellis-Harron-Turner como hipotexto del guion de Shame firmado por McQueen y Morgan y, en consecuencia, la existencia de una relación de hipertextualidad en sentido genettiano entre una película y otra. Con ello se quiere decir que difícilmente Shame sería tal cual es sin la previa existencia de American Psycho, respecto de la cual la película de McQueen sería el resultado de una transformación compleja e indirecta ${ }^{42}$. Al

\footnotetext{
${ }^{41}$ Así resumía una brillante idea introducida en la teoría literaria por Mijail Bajtín: "Any text is constructed as a mosaic of quotations; any text is the absorption and transformation of another" (Kristeva, 1986, p. 37).

${ }^{42} \mathrm{Al}$ respecto, véase Genette, 1989, pp. 14-20.
} 
respecto de este tipo de transformaciones el semiólogo francés manifiesta (1989, p. 262):

La transposición puede investirse en obras de vastas dimensiones, como Fausto o Ulysse, cuya amplitud textual y ambición estética y/o ideológica llegan a enmascarar o a hacer olvidar su carácter hipertextual, y esta productividad misma está ligada a la diversidad de los procedimientos transformacionales que emplea.

Por otro lado, Genette advierte de los peligros que entraña el hecho de que cuanto menos masiva y declarada es la relación de hipertextualidad -como es el caso que nos ocupa-, tanto más su análisis depende de una decisión interpretativa del receptor (1989, p. 19). Pero esto es justo lo que, creo, pretendería McQueen: no es hacer un remake de la obra de Ellis/Harron, sino más bien una reescritura o sobreescritura de lo más fundamental del argumento y de las intenciones metafóricas del hipotexto, que se podría encuadrar en lo que se ha llamado reescritura encubierta (Pardo García, 2010, pp. 84-86). Este tipo de reescritura fílmica, más difícilmente categorizable, desdibuja las líneas de filiación con su hipotexto mediante la diversidad de transformaciones operadas que afectan radicalmente tanto a los contenidos como a las formas. Para ilustrar este tipo de relación de hipertextualidad no declarada o abierta, Pardo García se sirve de la existente entre Los Otros (2001) de Alejandro Amenábar y The Turn of the Screw de Henry James, posiblemente a través de la mediación de sus adaptaciones fílmicas, como The Innocents (1961) de Jack Clayton. En nuestro caso, y en conclusión, creo que se puede considerar de la misma naturaleza hipertextual (la de la reescritura encubierta), la distancia que separa -o acerca, según se mire-Shame, el film de Steve McQueen, respecto de American Psycho, la novela de Bret Easton Ellis, a través de la fundamental intermediación de su versión cinematográfica, la película American Psycho dirigida por Mary Harron. 


\section{Referencias bibliográficas}

Algeo, J. (1991). Fifty Years Among the New Words: A Dictionary of Neologisms. Cambridge: Cambridge University Press.

Allen, G. (2000). Intertextuality. London-New York: Routledge.

Baelo Allué, S. (2002). The aesthetics of serial killing: Working against ethics in The Silence of the Lambs (1988) and American Psycho (1991), Atlantis. Revista de la Asociación Española de Estudios AngloNorteamericanos, 24.2, 7-24.

Díaz Gito, M.A. (2019). El Infierno, según Steve McQueen. Shame (2011) y las Hijas de Dánao, International Journal of the Classical Tradition, 26, en prensa.

Featherstone, M. (2016). Carnotopia: The Culture of Sadism in Nymphomaniac, Shame and Thanatomorphose. En J. Gwynne (Ed.), Transgression in Anglo-American Cinema: Gender, Sex and the Deviant Body (pp. 25-42), London-New York: Wallflower Press.

Genette, G. (1989). Palimpsestos. La literatura en segundo grado. Madrid: Taurus (=1982).

González Etxeberria, J. (2017). Epopeyas postmodernas y topografías infernales sin salida. En J. M. Losada \& A. Lipscomb (Eds.), Myth and Emotions (pp. 279-290). Cambridge: Cambridge Scholars Publishing.

Holtsmark, E.B. (2001). The Katabasis Theme in Modern Cinema. En M.M. Winkler (Ed.), Classical Myth and Culture in the Cinema (pp. 23-50). Oxford: Oxford University Press [=Classics and Cinema (1991)].

Holtsmark, E.B. (1997). Films and Ring Composition. KLEOS. Estemporaneo di Studi e Testi sulla Fortuna dell'Antico, 2, 271-274.

Kauffman, L. (2000-2001). American Psycho, Film Quarterly, 54.2, 41-45.

Kooijman, J. \& T. Laine (2003). American Psycho: A double portrait of serial yuppie Patrick Bateman, Post Script, 22.3, 46-57.

Kristeva, J. (1986). Word, Dialogue and Novel. En T. Moi (Ed.), The Kristeva Reader (pp. 34-61). New York: Columbia University Press.

Lee, C. (2013). Shopping and Slaying, Fucking and Flaying: Serial Consumption in American Psycho. En A. MacDonald (Ed.), Murders and Acquisitions: Representations of the Serial Killer in Popular Culture (pp. 105-122). New York: Bloomsbury.

Marinkovich, J. (1998-1999). El análisis del discurso y la intertextualidad, Boletín de Filología de la Universidad de Chile, 37, 729-742.

Pardo García, P.J. (2010). Teoría y práctica de la reescritura filmoliteraria (A propósito de las reescrituras de The Turn of the Screw). En J.A. Pérez 
Bowie (Ed). Reescrituras fílmicas. Nuevos territorios de la adaptación (pp. 45-102). Salamanca: Universidad.

Pérez Bowie, J.A. (ed.) (2010). Reescrituras fílmicas. Nuevos territorios de la adaptación. Salamanca: Universidad.

Pérez Bowie, J.A. (2008). Cine e Intertextualidad. En Idem, Leer el cine. La teoría literaria en la teoría cinematográfica (pp. 151-167). Salamanca: Universidad.

Robinson, D. (2006). The Unattainable Narrative: Identity, Consumerism and the Slasher Film in Mary Harron's American Psycho, CineAction, 68, 26-35.

Sánchez-Escalonilla, A. (2005). The Hero as a Visitor in Hell. The Descent into Hell in Film Structure, Journal of Popular Film and Television 32.4, 149-156.

Stam, R. (2005). Introduction: The Theory and Practice of Adaptation. En R. Stam \& A. Raengo (Edd.), Literature and Film. A Guide to the Theory and Practice of Film Adaptation (pp. 1-52, esp. 26-31). Malden-Oxford: Blackwell Publishing.

\section{Referencias cinematográficas}

Harron, M. (2000). American Psycho. United States of America: Lions Gate Home Entertainment.

McQueen, S. (2011). Shame. United Kingdom: Film4, See-Saw Films, UK Film Council. 